\title{
Net Nuptiality Tables for Males and Females in Pakistan: 1962-65
}

by

\author{
Mohammad AfZal AND NAUSHIN IFTIKHAR* \\ INTRODUCTION
}

The patterns of shifting of population from the stage of being single to being married by age and sex are of great demographic importance because of their significant role in determining the population composition and growth through family formation and fertility. The proportions of population getting married at different ages are of importance for the population planning programme since only married persons can be the potential producers of children in a society like Pakistan where illegitimate fertility is almost non-existant. Such proportions have also important bearings on social and economic characteristics like school attendance and labour force participation particularly of females. The trend in the number of marriages has important implications for housing programmes, community planning and for the enterprises like insurance companies who are concerned with providing life and health insurance of the
married couples.

In order to study the marriage patterns, a number of statistical measures like crude marriage rates, age-sex specific marriage rates and similar other rates have been used by demographers but the most refined device known is the Nuptiality Table. The term nuptiality is associated with the frequency of marriages and a Nuptiality Table provides the expected proportions of single persons who get married at different ages and also their average expected years to marriage from each age. This table is basically constructed following the same approach as the Life Table with marriages also being treated as a form of decrement for single persons in addition to mortality $[6, \mathrm{p} .1825]$.

In order to understand the concept of the Nuptiality Table, it is necessary to provide first a description of the nature of a simple Life Table and the basic requirements for its construction.

* Mohammad Afzal is Research Demographer and Naushin Iftikhar is Research Assistant at PIDE. The authors are thankful to J. Gilbert Hardee, Research Advisor, for his useful
suggestions in the earlier draft. 
A Life Table is a statistical model which describes the life history of a group of persons born at one time, as it passes through different years of life, experiencing specific mortality at different ages until every one of them dies. This table is generated through the application of a given set of age-specific mortality rates on a hypothetical cohort of persons assumed to have been born at one time, and provides the value of such functions as the probability of death at each age and the expected average life (or the years to death) beyond a specific
age. A Nuptiality Table is also modelled after the Life Table but it describes the effect of age-specific marriage rates on a hypothetical cohort of single persons as it passes through different ages. This table therefore gives proportions of a cohort of single males or females who would be getting married at various ages assuming that the marriage rates used in constructing the table would continue to prevail. Such table when constructed without accounting for the mortality effect is called Gross Nuptiality Table. If however the mortality effect is also taken into account in addition to attrition due to marriages, the table so constructed is called Net Nuptiality Table [9, Pp. 243-360]. This type of table provides the following information on the basis of given nuptiality and mortality rates:

(i) The pace at which a group of single persons is decreased by marriages and deaths;

(ii) The probability of single persons marrying at each year of age;

(iii) The average age at marriage;

(iv) The proportion of single persons who remain single at each age and the proportion of those who will eventually marry.

\section{SOME USES OF NET NUPTIALITY TABLES}

Just as the Life Table is an important instrument for the analysis of population dynamics, a Net Nuptiality Table provides an understanding of the patterns of entry into marital unions and the composition of population by marital status under given mortality rates. While a Life Table in itself provides such functions as death probabilities, number of survivors and expected years of life at each age, similarly a Net Nuptiality Table gives directly age-wise marriage probabilities, number of single (unmarried) survivors and expected years of single life remaining after taking into account attrition due to mortality.

The results provided by the functions of Net Nuptiality Table alongwith those of Life Table can be used for a number of purposes some of which are given below.

The survival ratios from Nuptiality Tables for males and females can be used to prepare future population projections of each sex for single and married persons separately. The projections for married persons can be of great use for population planning programmes, since these would in fact be the projections of potential users of the contraceptives.

Similarly the survival ratios from Net Nuptiality Table can be used to estimate migration patterns for single and married persons separately, just as survival ratios from a Life Table are used to estimate overall migration. 
Another use of Net Nuptiality Table is that by substracting the average years of single life remaining at age zero given by Nuptiality Table $\left({ }^{\circ} e^{\prime}\right)$ from the average expected life at age zero provided by a Life Table of corresponding sex we get expected years of life after marriage under given sets of mortality and marriage probabilities.

\section{DATA REQUIRED FOR NET NUPTIALITY TABLES}

As stated earlier, age-sex-specific mortality rates are the only requirement for constructing a simple Life Table. A Net Nuptiality Table requires age-sexspecific death probabilities from a given Life Table alongwtih age-sex-specific first marriage probabilities. For the computation of these two sets of probabilities, the main sources of data should be the vital registration system and the census, the former providing number of deaths and marriages according to age and sex and the latter giving population size. The vital registration system of Pakistan being highly defective and incomplete, cannot be used to provide the necessary data on death statistics [1]. Such data are, however, available from the Population Growth Estimation Project (PGE), which yielded estimates of vital rates on the basis of a country-wide sample for the years 1962 through 1965 [5]. Marriages in Pakistan are not covered by the official vital registration system, instead a new system requiring marriages to be registered in the local Union Council or Committee, was introduced as a consequence of the Muslim Family Law of 1961. This system has been yielding fairly useful records of marriages, but these records exist only in the shape of marriage registration forms and not in the shape of statistics. Unfortunately the data from these records have not been compiled and hence no country-wide consolidated statistics are available for marriages. ${ }^{1}$ In the absence of marriage data, the estimates of number of marriages at each age have been arrived at indirectly as described in the following section.

\section{METHODOLOGY}

In constructing separate male and female Net Nuptiality Tables for Pakistan, provided as Tables I and II, the age-sex-specific mortality probabilities have been taken from Complete Life Tables for Pakistan (1962-65) prepared by Yusaf and Farooqui [11] on the basis of data drawn from PGE. ${ }^{2}$ Due to nonavailability of a Life Table for singles, the Life Table for total population is being used assuming the mortality patterns for singles to be the same as the over-all population of the corresponding sex. The corresponding age-sex-specific marriage probabilities have, however, been worked out indirectly from age and sex distribution of population by marital status ${ }^{3}$ as provided by PGE for the year $1965[5$, p. 166]. For the construction of Nuptiality Tables the given population distribution was used in the following way to arrive at estimates of singles for each age in the Nuptiality Table.

(i) Out of the total population the ratio of single persons was computed for each age-group.

${ }^{1}$ The data from this source have however been used in some studies on age at marriage for the cities of Karachi and Lahore and also for a group of Punjab villages $[2,3,6,7]$.

The Complete Life Tables for West Pakistan based on Chandra-Deming estimates of mortality have been used in this study.

'The distribution of population exists in the form of 'never married' and 'ever married' categories, as such the marriage probabilities worked out in this paper refer to first marr iages only. 
(ii) Ratios for single years were then interpolated out of them;

(iii) These ratios were then multiplied with the number of survivors at each single age $\left(l_{x}\right)$ as given in the Complete Life Tables referred to above, giving the estimated number of single survivors to the respective ages $\left(l^{\prime} x\right)$ in the Nuptiality Table

In order to arrive at estimates of marriage probabilities at each age, the first step was to estimate the number of marriages. This has been done by using the number of single survivors and the number of total survivors (married and unmarried inclusive), in the following way:-

$l_{\mathrm{x}} \quad=$ number of survivors at age $\mathrm{x}$.

$I_{\mathrm{x}} \quad=$ number of single survivors at age $\mathrm{x}$.

$l_{\mathrm{x}}-l_{\mathrm{x}}^{\prime}=$ number of married survivors at age $\mathrm{x}$.

$q_{\mathrm{x}} \quad=$ the probability of death between the age $\mathrm{x}$ and $(\mathrm{x}+1)$

$p_{\mathrm{x}}=1-q_{\mathrm{x}}=$ the probability of surviving between age $\mathrm{x}$ and $(\mathrm{x}+1)$

Since $\left(l_{\mathrm{x}}-l_{\mathrm{x}}^{\prime}\right)$ is the number of married persons who are survivors of those already married at age $(x-1)$ and the singles who got married between the age $(x-1)$ and $x$, the estimate of the original group of which $\left(l_{x}-l_{x}^{\prime}\right)$ are the survivors, is given by $l_{x}-l_{x}$. The estimated number of marriages between

$$
p_{\mathrm{x}-1}
$$

the ages $(\mathrm{x}-1)$ and $\mathrm{x}$ is given by $\frac{l_{\mathrm{x}}-l_{\mathrm{x}}^{\prime}}{p_{\mathrm{x}-1}}-\left(l_{\mathrm{x}-1}-l_{\mathrm{x}-1}^{\prime}\right)-\mathrm{M}_{\mathrm{x}-1}$

Similarly $M_{\mathbf{x}}$, the number of marriages between $x$ and $(x+1)$ is given by

$$
\frac{l_{\mathrm{x}+1}-l_{\mathrm{x}+1}^{\prime}}{p_{\mathrm{x}}}-\left(l_{\mathrm{x}}-l_{\mathrm{x}}^{\prime}\right)=\mathrm{M}_{\mathbf{x}}
$$

The marriage probability between age $x$ and $(x+1)$ is represented in a Nuptiality Table by the symbol $n_{x}$ which is given in the study by the following:

$$
\mathrm{n}_{\mathrm{x}}=\frac{\mathbf{M}_{\mathrm{x}}}{l_{\mathrm{x}}^{\prime}}=\frac{\frac{l_{\mathrm{x}+1}-l_{\mathrm{x}+1}^{\prime}}{p_{\mathrm{x}}}-\left(l_{\mathrm{x}}-l_{\mathrm{x}}^{\prime}\right)}{l_{\mathrm{x}}^{\prime}}
$$
as $1000 n_{x}$.

In the Nuptiality Table this measure forms the first column and is given

The second column in the table gives probability of death, between age $x$ Tand $(x+1)$ and is symbolized as $q_{x}$. This has been taken directly from the Complete Life Table of Pakistan and in this table is given as $1000 \mathrm{q}_{\mathrm{x}}$. The third column gives number of single survivors at age $\mathrm{x}$ or $l^{\prime} \mathrm{x}$. The estimation procedure for this measure has been already described in (A) above.

The fourth column gives deaths at age $x$ while single which is represented by the symbol $d_{x}^{\prime}$ in Nuptiality Table and is given by the following formula;

$$
\mathrm{d}_{\mathrm{x}}^{\prime}=\mathrm{q}_{\mathrm{x}}\left(1-\frac{\mathrm{n}_{\mathrm{x}}}{2}\right) l_{\mathrm{x}}
$$


Column (5) in the table gives estimates of first marriages out 100,000 born alive which is the radix of Nuptiality Table. These are represented by the symbol $v_{x}^{\prime}$ which is given by the formula:

$$
v^{\prime}{ }_{x}=l_{x}^{\prime}-d^{\prime}{ }_{x}-l_{x+1}^{\prime}
$$

The next column $N^{\prime}$ gives first marriages at each age $x$ and at later ages and is given by $\sum_{x=10}^{55+} v_{x}^{\prime}$. Column (7) provides percentage of $N_{x}^{\prime}$ out of corresponding single survivors $l_{\mathrm{x}}$. Column (8) in the table gives stationary population at different ages. The corresponding symbol for this column is $L_{x}^{\prime}$ which stands for the person-years lived by single persons between the ages $x$ and $(x+1)$. This is given by the following formula:

$$
L_{x}^{\prime}=\frac{1}{2}\left(l_{x}^{\prime}+l_{x+1}^{\prime}\right)+\frac{1}{2}\left(d_{x+1}^{\prime}+v_{x+1}^{\prime}-d_{x-1}^{\prime}-v_{x-1}^{\prime}\right)
$$

Column (9) gives the values of $T_{x}^{\prime}$ which represents the number of person-years lived by single persons at age $x$ and at all later ages and is given by $\Sigma L_{x}^{\prime}$. The last column (10) gives the estimates of expected years of single life remaining at start of age $x$. In other words the column provides expected average years to marriage taking into account the effect of death. The symbol corresponding to this estimate is ${ }^{0} e^{\prime}$ which is given by the formula $o_{e^{\prime}}{ }_{x}=\frac{T_{x}^{\prime}}{l_{x}^{\prime}}$.

Following the procedure described above, separate Net Nuptiality Tables have been prepared for males and females in Pakistan, (Tables I and II), which correspond to the period 1962-65 so far as the mortality effect is concerned whereas the estimates of marriages represent the period 1964-65. The Net Nuptiality Tables for Pakistan have been constructed in this study considering age 10 as minimum for males as well as females keeping in view the distribution of population by marital status. On the same basis the maximum age group for males has been taken as 55 and over, and for females as 50 and over.

As is true for most of the statistical estimates, the results provided in Net Nuptiality Tables may suffer from such limitations as the errors of reporting and coverage in the basic data and the errors of estimates affecting subsequently the age-sex specified death probabilities as well as marriage probabilities used in this study. So far as the estimates of mortality are concerned there is no better substitute to the estimates provided by PGE in Pakistan, which have been the basis of complete Life Tables used in this study. However, in order to arrive at estimates of marriage probabilities, it would have been better if direct estimates of age-wise number of marriages were available for the construction of the Nuptiality Tables. Since such data do not exist for the country as a whole, the indirect estimates arrived at in the present study would be a useful substitute.

\section{SALIENT RESULTS}

The results provided under each column of the Nuptiality Tables persented in this paper are self-explanatory in the light of the description of each column given earlier. We shall, however, discuss here some of the main results which are provided in columns (1), (7) and (10) in the corresponding tables for males and females. Before these results are discussed, it must be kept in view 
that the estimates provided in the Net Nuptiality Tables are the result of two types of age specific attrition probabilities-the death probabilities and the marriage probabilities. Thus the sex differentials in these two type of probabilities bring about the differentials in the results for males and females.

Referring first to column (1), it is observed that for females, marriage probabilities are higher in younger ages than the corresponding probabilities for males, but in the higher ages the male probabilities remain at a relatively higher level compared to females. This confirms earlier studies on age at marriage in that the females get married mostly in younger ages as compared to males.

Column (7), which provides percentage of marriages at age $x$ and at all later ages $\left(\% \mathrm{~N}^{\prime}\right)$, out of survivors at each age, shows that out of the whole cohort at age zero the percentage for males was 70.8 while for females it was 68.0. This means that number of female marriages throughout the age-span out of the initial cohort is less as compared to males, which is primarily because of higher female mortality in ages under 10 as compared to males. In the higher ages, however, the situation changes in favour of females, their marrage percentages becoming higher than the males. The females retain this advantageous position till the age 30 , after which their marrige percentages decline with a greater pace while the corresponding percentages for males taper off slowly. These results also support the conclusions drawn out of the first column that the female marriages are more concentrated at younger ages while for males they extend to higher ages with a relatively higher frequency as compared to females.

\section{Average Years to Marriage}

Let us now refer to column (10) which is the last column of the Nuptiality Tables. This column provides years of single life remaining at start of age $x$, or, in other words, the average expected yeirs to marriage for those singles surviving up to a particular age $\left({ }^{\circ} \mathrm{e}_{\mathrm{x}}^{\prime}\right)$. The resu: ${ }^{\prime}=$ under this column out of the tables presented in this study show that the average expected years to marriage in Pakistan at age zero (or at birth) are 19.39 for males and 14.19 for females. Similarly for higher ages the corresponding estimates are provided for average years to marriage beyond those ages. These estimates show that years to marriage remain higher for males than for females up to the age 27 after which the estimates for the two sexes do not differ much.

\section{Average Age at Marriage}

Average years to marriage are not to be confused with the concept of average age at marriage, since in the former, by taking into accout the years of life of singles who die before marriage, the average per person in the original cohort becomes lower than the average age at marriage, which is the average of only of those who get married. We can however, derive the average age at marriage for males and females from their respective Net Nuptiality Tables by adding to the minimum age at marriage, the averarge expected years to marriage beyond that age. Since the minimum age in the Nuptiality Tables has been taken as 10 , the estimate average age at marriage is given by $\left(10+{ }^{\circ} \mathrm{e}_{10}^{\prime}\right)$ which comes to be 25 for males and 19 for females. These estimates are almost the same as those arrived at by Alam [4] from the PGE data for 1964 (24.7 for 
males and 19 for females), but are slightly higher than the estimates by Sadiq [10] for 1961 (23.5 for males and 17.6 for females), which give some indication of possible rise in the age at marriage. It may also be of interest to know that the estimates of age at marriage of females in Karachi, Lahore city and some rural areas of Punjab $[2,3,7]$ made out of the marriage registration forms give almost the same results as the Nuptiality Tables. For males the average age at marriage was lower in rural study areas (22.5) but for Karachi and Lahore, the estimates were almost the same as those given by the Nuptiality Tables for males.

\section{Average Years of Life after Marriage}

Substracting the expected average years of single life at age zero from the average expected life at age zero from the corresponding Complete Life Tables for males and females [11], the estimates of expected years of life after marriage for males come to 30.4 years $(49.79-19.39)$ and for females as 33.69 years $(47.88-14.19)$.

\section{REFERENCES}

1. Afzal, Mohammad and Tauheed Ahmad, "Limitations of Vital Registrations in Pakistan as against Sample Population Estimation Projects-A Case Study of Rawalpindi". (forthroming).

2. Afzal, Mohammad, Lee L. Bean and Imtiazuddin Hussain, "Muslim Marriages: Age, Mehr and Social Status" Pakistan Development Review, Vol XII, No. 1, Spring, 1973.

3. Afzal, Mohammad, M. Iqbal Hashmi and N.H. Nizami, "Marriage Patterns in a Rural Agglomeration", Pakistan Development Review Vol XII, No. 3, Autumn, 1973.

4. Alam, Syed Iqbal, "Age at Marriage in Pakistan", Pakistan Devolopment Review, Vol. VIII No. 3, Autumn, 1968.

5. Farooqi, M. Nasim Iqbal and Ghazi Mumtaz Farooq, "Final Report of the Population Growth Estimation Experiment: 1962-1965" PIDE (1971).

6. Grabill, Wilson H., "Some Demographic Implications of Nuptiality Rates", Proceedings of International Population Conference, London 1969, Vol III, IUSSP, Leige (1971).

7. Khan, Nafis Ahmad, "Muslim Marriages in the Walled City of Lahore" Unpublished research report submitted for Diploma in Demography to the Punjab University (1972).

8. Korson, Henry J., "Age and Social Status at Marriage in Karachi 1961-64”, Pakistan Development Review, Vol. V, No. 4, Winter, 1965.

9. Sabeland, Walt and Paul C. Glick, "First Marriage Decrement Tables by Colour and Sex for the United States in 1958-60", Demography. 6(3), August 1969, as quoted in Shryock and Seigel, "The Methods and Materials of Demography", U.S. Deptt. of Commerce, May 1973.

10. Sadiq Nasim M., "Estimation of Nuptiality and its Analysis from the Census Data of Pakistan", Pakistan Development Review, Vol. V, No. 2,
Summer, 1965.

11. Yusaf, Farhat and Nasim Iqbal Farooqui, "Complete Life Tables For Pakistan and Provinces: 1962-1965", Research Report No. 85, PIDE, 


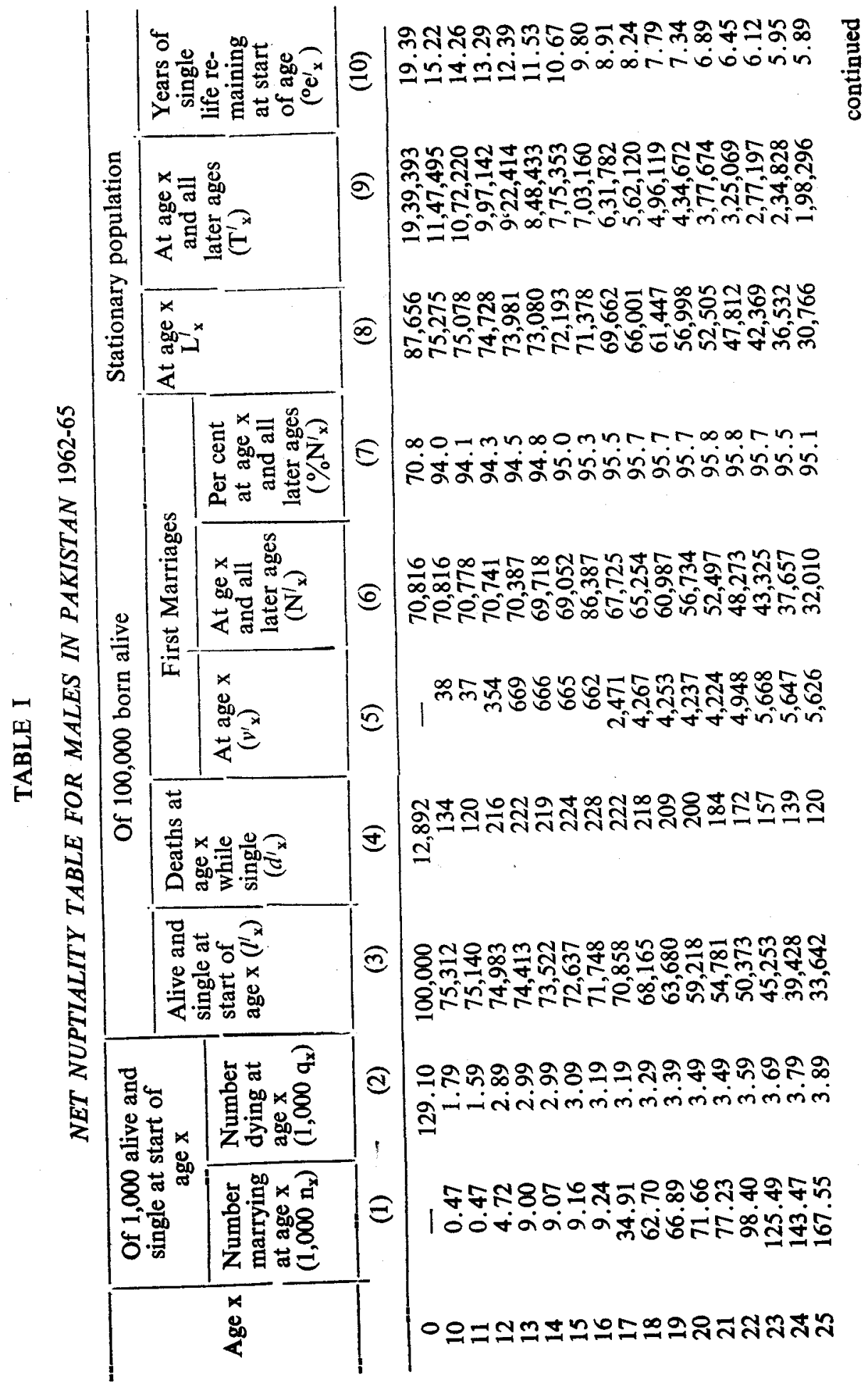




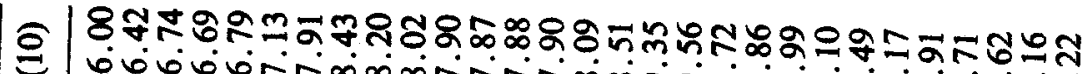

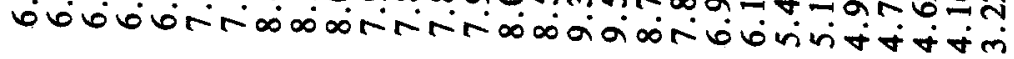

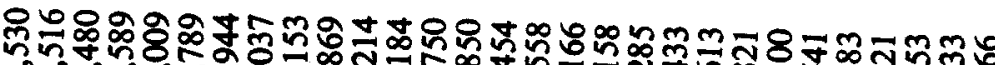

(9) กํ.

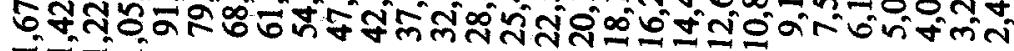

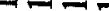

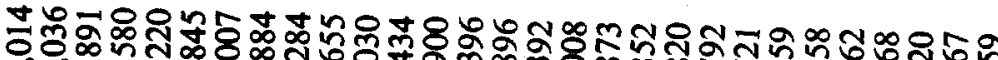

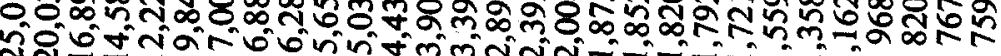

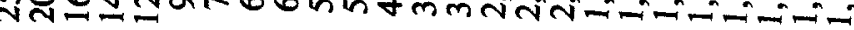

S

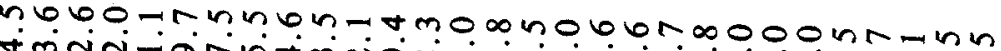

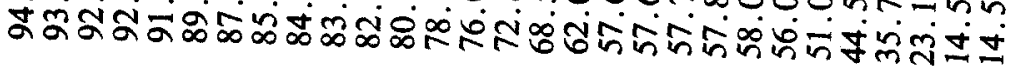

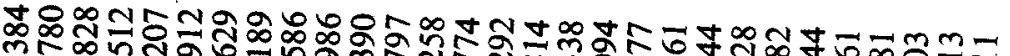
m

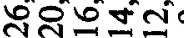

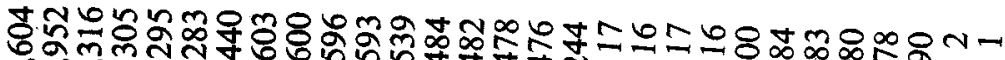

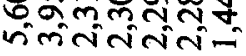

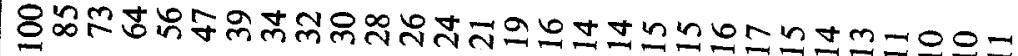

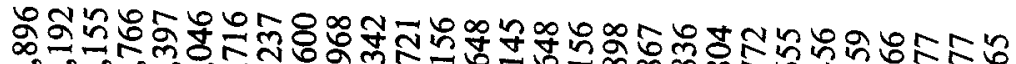

तิ

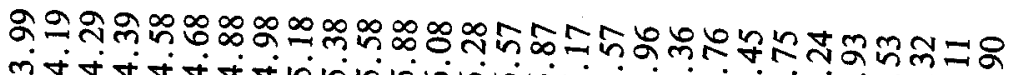

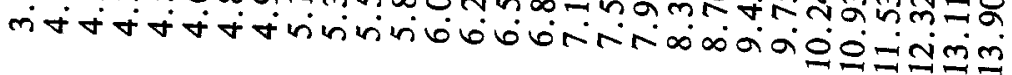

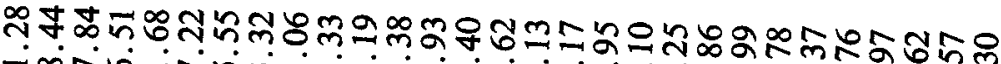

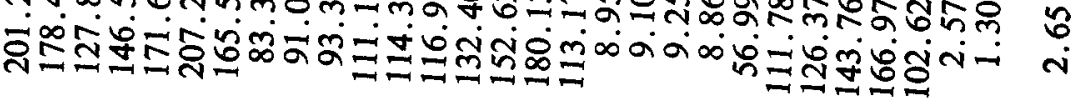

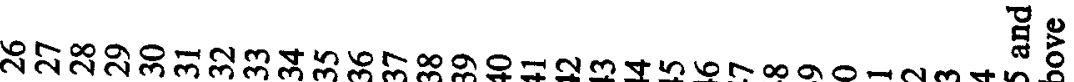




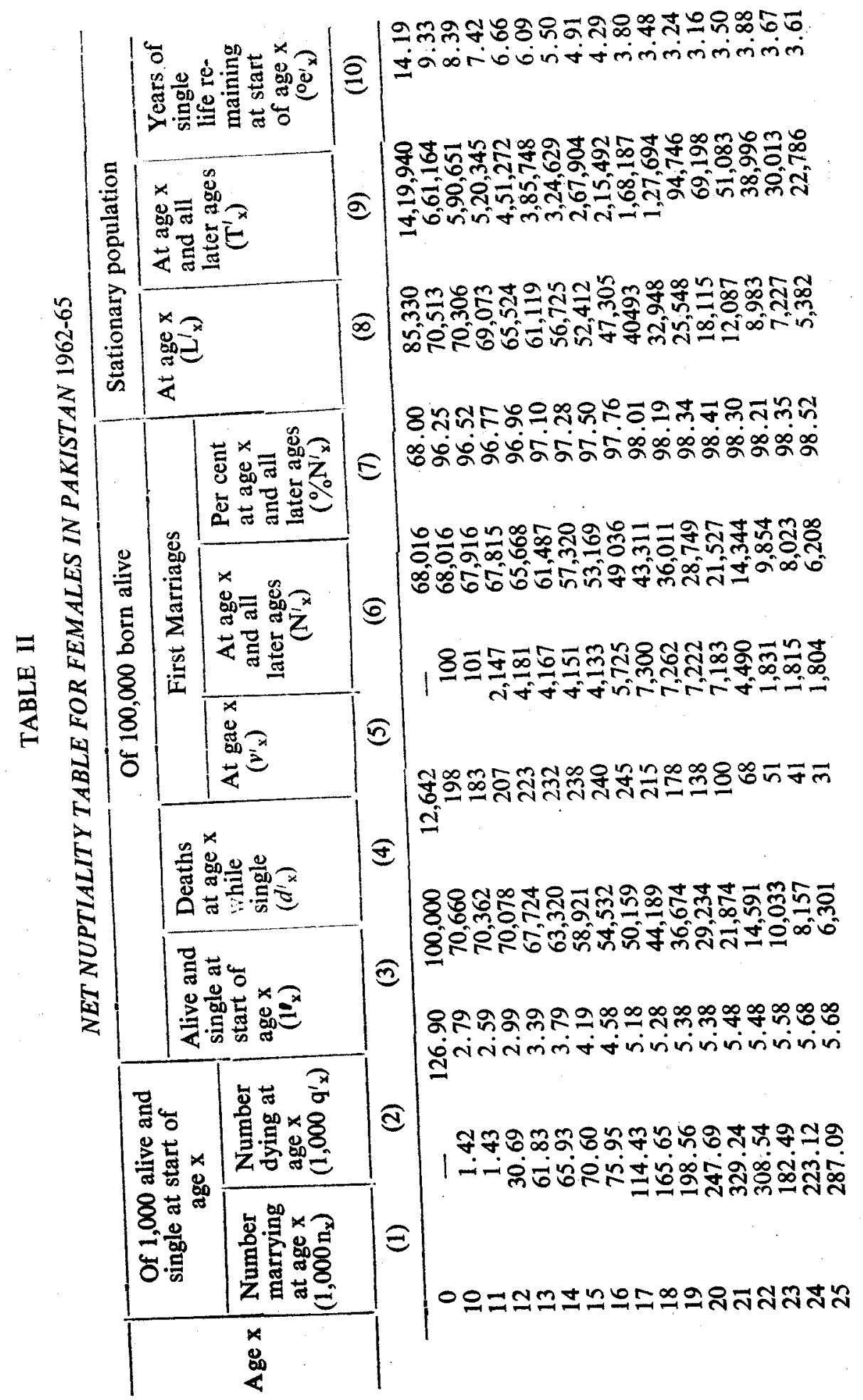




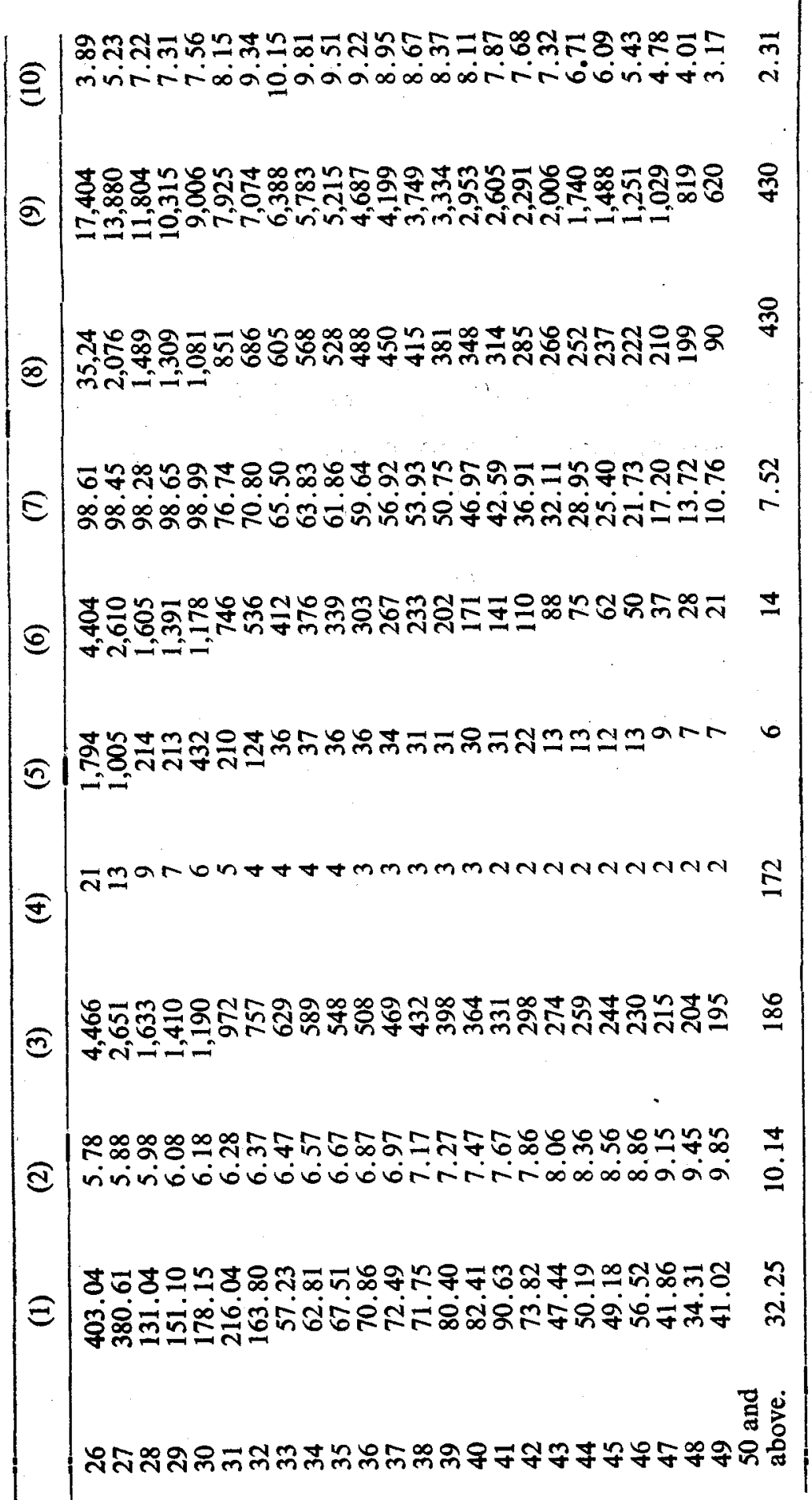

